\title{
Avaliação econômica da utilização de diferentes níveis de polpa cítrica com ou sem adição de complexo enzimático nas dietas de suínos
}

\author{
[Economic evaluation of the use of different levels of citrus pulp with or without the addition of enzyme \\ complex in the diets of pigs] \\ A.B. Amorim ${ }^{1}$, M.C. Thomaz $^{2}$, U.S. Ruiz ${ }^{1}$, L.A.F. Pascoal ${ }^{1}$, P.H. Watanabe ${ }^{1}$, J.F. Martinez ${ }^{3}$, \\ E. Daniel $^{1}$, M.I.E.G. Martins ${ }^{4}$, G.C.I.H. Masson ${ }^{1}$ \\ ${ }^{1}$ Aluno de pós-graduação - FCAV - UNESP - Campus de Jaboticabal \\ ${ }^{2}$ Departamento de Zootecnia - FCAV - UNESP \\ Campus de Jaboticabal - Via de acesso Prof. Paulo Donato Castellani, s/n \\ 14884-900 - Jaboticabal, SP \\ ${ }^{3}$ Aluna de graduação - FCAV-UNESP, Jaboticabal, SP \\ ${ }^{4}$ Departamento de Economia Rural - FCAV-UNESP, Jaboticabal, SP
}

\begin{abstract}
RESUMO
Avaliou-se economicamente o efeito da inclusão de 0, 5, 10 e 15\% de polpa cítrica (PC), com ou sem adição do

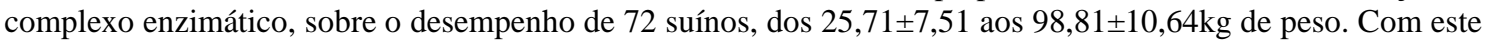
peso final, os animais foram abatidos, e dos valores (R\$) da carcaça, incluindo os índices de bonificação, foram descontados o valor de compra dos animais e os custos com alimentação, de acordo com cada tratamento. Para os custos com alimentação, foi observado aumento linear $(\mathrm{P}=0,0190)$, enquanto para as receitas bruta $(\mathrm{P}=0,0328)$ e líquida $(\mathrm{P}=0,0013)$ parciais foram encontradas reduções lineares em função das porcentagens de PC com ou sem a adição do complexo enzimático. Considerando-se a evolução dos preços do milho, farelo de soja e do suíno durante o ano de 2008, foram determinados 12 cenários diferentes para a receita líquida parcial e, em todos eles, foi observada redução linear em função da inclusão da PC, com ou sem adição do complexo enzimático. Conclui-se que a utilização de PC, com ou sem adição do complexo enzimático, não reduziu os custos com alimentação, não sendo economicamente viável sua inclusão nas rações de suínos em crescimento e terminação.
\end{abstract}

Palavras-chave: suínos, custo com alimentação, receita bruta parcial, receita líquida parcial

\begin{abstract}
An economic evaluation was done in order to evaluate the effect of the inclusion of 0, 5, 10 and 15\% of citrus pulp (PC), with or without the addition of the enzyme complex, on the performance of 72 pigs from $25.71 \pm 7.51$ to $98.81 \pm 10.64 \mathrm{~kg}$ of body weight. The animals were slaughtered when they reached $98.81 \mathrm{~kg}$. The purchase value of the animals and feed costs $(R \$)$ were discounted from the carcass value, including subsidy rates $(R \$)$. A linear increase $(P=0.0190)$ was observed, while linear reductions were observed for the gross receipts $(P=$ $0.0328)$ and net $(P=0.0013)$ partials, due to the inclusion of $P C$ in the diet with or without the enzyme complex. Considering the evolution of corn, soybean meal and pig prices during 2008, there were some 12 different scenarios for partial and net income determined and in all of them, linear reductions were observed due to the inclusion of PC in the diet with or without the enzyme complex. The use of PC with or without the addition of the enzyme complex was unable to reduce the costs of feed.
\end{abstract}

Keywords: swine, cost of food, gross income partial, net income partial

\section{INTRODUÇÃO}

O milho, principal fonte energética das dietas de suínos, às vezes é utilizado para a produção de

Recebido em 15 de março de 2010

Aceito em 14 de julho de 2011

E-mail: alessandrozoo@gmail.com etanol, como é o caso dos Estados Unidos da América, gerando grandes problemas para o setor, uma vez que este cereal representa cerca de $70 \%$ das dietas de suínos. Assim, é necessário e importante que se encontrem ingredientes 
alternativos para solucionar ou, pelo menos, amenizar essa dependência.

De maneira geral, dois pontos devem ser observados para se obter redução dos custos com alimentação. Um se refere ao estudo de ingredientes alternativos, visando a suas inclusões nas rações, e o outro diz respeito ao reconhecimento da potencialidade e da restrição ao uso desses ingredientes nas diferentes fases de produção (Bellaver e Ludke, 2004).

Neste contexto, o Brasil destaca-se por ser um dos maiores produtores de citros do mundo (História..., 2009), sendo $75 \%$ da produção consumida na forma de suco, havendo, assim, grande disponibilidade de resíduos na indústria. Dentre os resíduos, o mais conhecido é a polpa cítrica (PC), que apresenta custo relativamente baixo e, dependendo da época do ano, com valores nutricionais favoráveis para utilização nas rações de suínos, tornando-se um possível substituto parcial ao milho.

Entretanto, por se tratar de um subproduto, apresenta um perfil energético diferente do milho, com menor digestibilidade, a qual pode ser melhorada com a suplementação de enzimas. Bhat (2000) relatou que a suplementação de enzimas, pode reduzir os custos da suinocultura, por possibilitar a utilização de ingredientes com preços menores, e concluiu, ainda, que mais estudos seriam necessários para recomendar a combinação correta de enzimas exógenas para uma ampla utilização na dieta para suínos.

Na criação de suínos, outro ponto de importância é o da tipificação de carcaça. Estudos têm-se desenvolvido com o objetivo de estimular a produção de carcaças com maior aceitação no mercado e melhorar a remuneração do produtor, e sabe-se que várias empresas bonificam o suinocultor por produzir carcaça de melhor qualidade (Guidoni, 2000). Assim, qualquer tentativa que vise reduzir o custo com alimentação pode refletir sobre a eficiência econômica da suinocultura (Saraiva et al., 2006), e há uma tendência atual, motivada principalmente por fatores econômicos e ambientais, em substituir grãos de cereais por subprodutos, tornando a polpa cítrica economicamente atraente.
Este trabalho teve o objetivo de analisar economicamente a inclusão de diferentes porcentagens de polpa cítrica, com ou sem adição do complexo enzimático, para suínos nas fases de crescimento e terminação.

\section{MATERIAL E MÉTODOS}

A análise econômica da inclusão de diferentes porcentagens de polpa cítrica, com ou sem adição do complexo enzimático nas dietas de suínos, foi baseada nos dados do ensaio de desempenho de 72 suínos, machos castrados, da linhagem Topigs, com idade inicial de 70 dias e média de peso de $25,71 \pm 7,51 \mathrm{~kg}$, alojados em baias individuais de alvenaria, com $2,55 \mathrm{~m}^{2}$ cada, providas de comedouros semiautomáticos e bebedouros, avaliados no período de junho a agosto de 2008 .

Os animais foram distribuídos entre oito tratamentos: DC - dieta-controle, composta principalmente por milho e farelo de soja; DCE dieta-controle mais o complexo enzimático; DPC5 - dieta composta principalmente por milho e farelo de soja e inclusão de $5 \%$ de PC; DPC5E - dieta composta principalmente por milho e farelo de soja e inclusão de $5 \%$ de PC mais o complexo enzimático; DPC10 - dieta composta principalmente por milho e farelo de soja e inclusão de $10 \%$ de PC; DPC10E - dieta composta principalmente por milho e farelo de soja e inclusão de $10 \%$ de PC mais o complexo enzimático; DPC15 - dieta composta principalmente por milho e farelo de soja e inclusão de 15\% de PC; DPC15E - dieta composta principalmente por milho e farelo de soja e inclusão de $15 \%$ de PC mais o complexo enzimático.

As dietas foram isonutritivas e de acordo com as exigências nutricionais mínimas recomendadas por Rostagno et al. (2005), considerando as seguintes fases: 1 - dos 70 aos 101 dias de idade; 2 - dos 102 aos 130 dias de idade; 3 - dos 131 aos 143 dias de idade. Para a formulação das dietas, foram utilizados os seguintes valores da PC: $23,1 \%, 18,5 \%, 4,3 \%, 6,9 \%, 1677,27 \mathrm{kcal}$ $\mathrm{EM} / \mathrm{kg}, \quad 1,4 \%$ e $0,4 \%$ para fibra em detergente neutro, fibra em detergente ácido, amido, proteína bruta, energia metabolizável, 
cálcio e fósforo, respectivamente. As dietas experimentais estão apresentadas nas Tab. 1, 2 e 3 para as fases 1,2 e 3 , respectivamente. O complexo enzimático era composto por xylanase, $\beta$-glucanase, celulase, pectinase e protease, sendo adicionados $5 \mathrm{~g} / 100 \mathrm{~kg}$ de ração.
Os preços dos ingredientes que compuseram as rações foram os praticados em Jaboticabal, SP, nos meses de junho a agosto, sendo o custo com alimentação determinado a partir do consumo total de ração de cada animal durante o período experimental e do custo do $\mathrm{kg}$ da dieta.

Tabela 1. Composições centesimal e nutricional das dietas experimentais utilizadas na fase 1 (dos 70 aos 101 dias de idade) dos suínos

\begin{tabular}{|c|c|c|c|c|}
\hline \multirow{2}{*}{ Ingrediente, \% } & \multicolumn{4}{|c|}{ Polpa cítrica, \% } \\
\hline & $0^{(1)}$ & 5 & 10 & 15 \\
\hline Milho & 69,107 & 62,998 & 56,976 & 50,715 \\
\hline Farelo de soja & 26,772 & 27,075 & 27,360 & 27,690 \\
\hline Polpa cítrica & - & 5,000 & 10,000 & 15,000 \\
\hline Fosfato bicálcico & 1,235 & 1,244 & 1,247 & 1,257 \\
\hline Calcário calcítico & 0,527 & 0,340 & 0,114 & - \\
\hline Óleo de soja & 0,419 & 1,373 & 2,300 & 3,304 \\
\hline L- Lisina. $\mathrm{HCl}(78,4 \%)$ & 0,275 & 0,280 & 0,286 & 0,290 \\
\hline DL - Metionina (99,0\%) & 0,078 & 0,094 & 0,110 & 0,127 \\
\hline L - Treonina $(98,0 \%)$ & 0,067 & 0,079 & 0,091 & 0,103 \\
\hline L - Triptofano (99,0\%) & 0,001 & 0,002 & 0,004 & 0,006 \\
\hline Suplementação mineral ${ }^{(2)}$ & 0,050 & 0,050 & 0,050 & 0,050 \\
\hline Suplementação vitamínica ${ }^{(3)}$ & 0,100 & 0,100 & 0,100 & 0,100 \\
\hline Sal comum & 0,354 & 0,350 & 0,347 & 0,343 \\
\hline Inerte/Complexo enzimático ${ }^{(4)}$ & 1,005 & 1,005 & 1,005 & 1,005 \\
\hline BHT & 0,010 & 0,010 & 0,010 & 0,010 \\
\hline Total & 100 & 100 & 100 & 100 \\
\hline \multicolumn{5}{|l|}{ Composição calculada ${ }^{(5)}$} \\
\hline Energia metabolizável, kcal/kg & 3230 & 3230 & 3230 & 3230 \\
\hline Proteína bruta, \% & 18,25 & 18,25 & 18,25 & 18,25 \\
\hline Amido, \% & 46,83 & 43,09 & 39,35 & 35,46 \\
\hline FDN, \% & 11,93 & 12,31 & 12,69 & 13,05 \\
\hline FDA, \% & 4,53 & 5,32 & 6,10 & 6,87 \\
\hline Lisina dig., \% & 1,03 & 1,03 & 1,03 & 1,03 \\
\hline Metionina dig., \% & 0,35 & 0,36 & 0,37 & 0,38 \\
\hline Metionina + Cistina dig., \% & 0,62 & 0,62 & 0,62 & 0,62 \\
\hline Treonina dig., \% & 0,67 & 0,67 & 0,67 & 0,67 \\
\hline Triptofano dig., \% & 0,19 & 0,19 & 0,19 & 0,19 \\
\hline Cálcio, \% & 0,63 & 0,63 & 0,63 & 0,68 \\
\hline Fósforo disponível, \% & 0,33 & 0,33 & 0,33 & 0,33 \\
\hline Potássio, \% & 0,69 & 0,72 & 0,75 & 0,78 \\
\hline Sódio, \% & 0,18 & 0,18 & 0,18 & 0,18 \\
\hline
\end{tabular}

${ }^{1}$ Polpa cítrica, com ou sem complexo enzimático. ${ }^{2}$ Níveis de garantia por kg de ração: Cobre - 30mg, Zinco 160mg, Iodo - 1,900mg, Ferro - 100mg, Manganês - 70mg, Selênio - 0,075mg. ${ }^{3}$ Níveis de garantia por kg de ração: Vit. A - 10000UI, Vit. D3 - 2500UI, Vit. E - 18,12mg, Ácido fólico - 0,75mg, Pantotenato de cálcio - 20mg, Biotina - 6mg, Niacina - 30mg, Piridoxina - 2,50mg, Riboflavina - 0,70mg, Tiamina - 2,50mg, Vit. B12 - 37,50 mcg, Vit. K3 - 12,5mg, Colina - 783mg. ${ }^{4} 5$ g de complexo enzimático por $100 \mathrm{~kg}$ de ração. ${ }^{5}$ Valores nutricionais dos ingredientes propostos por Rostagno et al. (2005), exceto polpa cítrica. 
Tabela 2. Composições centesimal e nutricional das dietas experimentais utilizadas na fase 2 (dos 102 aos 130 dias de idade) dos suínos

\begin{tabular}{|c|c|c|c|c|}
\hline \multirow{2}{*}{ Ingrediente, \% } & \multicolumn{4}{|c|}{ Polpa cítrica, \% } \\
\hline & $0^{(1)}$ & 5 & 10 & 15 \\
\hline Milho & 70,783 & 66,778 & 60,712 & 54,649 \\
\hline Farelo de soja & 23,633 & 23,826 & 24,118 & 24,412 \\
\hline Polpa cítrica & - & 5,000 & 10,000 & 15,000 \\
\hline Fosfato bicálcico & 0,988 & 0,987 & 0,995 & 1,002 \\
\hline Calcário calcítico & 0,549 & 0,416 & 0,209 & - \\
\hline Óleo de soja & 0,485 & 1,105 & 2,045 & 2,984 \\
\hline L - Lisina. HCl (78,4\%) & 0,276 & 0,280 & 0,285 & 0,291 \\
\hline DL - Metionina (99,0\%) & 0,064 & 0,074 & 0,091 & 0,107 \\
\hline L - Treonina $(98,0 \%)$ & 0,062 & 0,070 & 0,082 & 0,094 \\
\hline $\begin{array}{l}\text { L - Triptofano (99,0\%) } \\
\text { Suplementação mineral }\end{array}$ & $\begin{array}{c}- \\
0,050\end{array}$ & $\begin{array}{l}0,001 \\
0,050\end{array}$ & $\begin{array}{l}0,004 \\
0,050\end{array}$ & $\begin{array}{l}0,005 \\
0,050\end{array}$ \\
\hline Suplementação vitamínica ${ }^{(3)}$ & 0,070 & 0,070 & 0,070 & 0,070 \\
\hline Sal comum & 0,330 & 0,328 & 0,324 & 0,321 \\
\hline Inerte/Complexo enzimático ${ }^{(4)}$ & 2,700 & 1,005 & 1,005 & 1,005 \\
\hline BHT & 0,010 & 0,010 & 0,010 & 0,010 \\
\hline Total & 100 & 100 & 100 & 100 \\
\hline \multicolumn{5}{|l|}{ Composição calculada ${ }^{(5)}$} \\
\hline Energia metabolizável, kcal/kg & 3230 & 3230 & 3230 & 3230 \\
\hline Proteína bruta, \% & 17,07 & 17,07 & 17,07 & 17,07 \\
\hline Amido, \% & 47,42 & 44,95 & 41,21 & 37,47 \\
\hline FDN, \% & 11,67 & 12,28 & 12,66 & 13,04 \\
\hline FDA, \% & 4,35 & 5,19 & 5,98 & 6,76 \\
\hline Lisina dig., \% & 0,95 & 0,95 & 0,95 & 0,95 \\
\hline Metionina dig., \% & 0,32 & 0,33 & 0,34 & 0,34 \\
\hline Metionina + Cistina dig., \% & 0,57 & 0,57 & 0,57 & 0,57 \\
\hline Treonina dig., \% & 0,62 & 0,62 & 0,62 & 0,62 \\
\hline Triptofano dig., \% & 0,17 & 0,17 & 0,17 & 0,17 \\
\hline Cálcio, \% & 0,60 & 0,60 & 0,60 & 0,59 \\
\hline Fósforo disponível, \% & 0,28 & 0,28 & 0,28 & 0,28 \\
\hline Potássio, \% & 0,65 & 0,67 & 0,70 & 0,73 \\
\hline Sódio, \% & 0,17 & 0,17 & 0,17 & 0,17 \\
\hline
\end{tabular}

${ }^{1}$ Polpa cítrica, com ou sem complexo enzimático. ${ }^{2}$ Níveis de garantia por kg de ração: Cobre - $30 \mathrm{mg}$, Zinco 160mg, Iodo $-1,900 \mathrm{mg}$, Ferro $-100 \mathrm{mg}$, Manganês $-70 \mathrm{mg}$, Selênio $-0,075 \mathrm{mg} .{ }^{3}$ Níveis de garantia por kg de ração: Vit. A - 10000 UI, Vit. D3 - 2500 UI, Vit. E - 18,12mg, Ácido fólico - 0,75mg, Pantotenato de cálcio 20mg, Biotina - 6mg, Niacina - 30mg, Piridoxina - 2,50mg, Riboflavina - 0,70mg, Tiamina - 2,50mg, Vit. B12 $37,50 \mathrm{mcg}$, Vit. K3 - 12,5mg, Colina - 783mg. ${ }^{4} 5 \mathrm{~g}$ de complexo enzimático por $100 \mathrm{~kg}$ de ração. ${ }^{5}$ Valores nutricionais dos ingredientes propostos por Rostagno et al. (2005), exceto polpa cítrica. 
Avaliação econômica da utilização...

Tabela 3. Composições centesimal e nutricional das dietas experimentais utilizadas na fase 3 (dos 131 aos 143 dias de idade) dos suínos

\begin{tabular}{|c|c|c|c|c|}
\hline \multirow{2}{*}{ Ingrediente, \% } & \multicolumn{4}{|c|}{ Polpa cítrica, \% } \\
\hline & $0^{(1)}$ & 5 & 10 & 15 \\
\hline Milho & 76,703 & 72,148 & 66,118 & 59,826 \\
\hline Farelo de soja & 19,608 & 19,828 & 20,119 & 20,456 \\
\hline Polpa cítrica & - & 5,000 & 10,000 & 15,000 \\
\hline Fosfato bicálcico & 0,818 & 0,819 & 0,826 & 0,834 \\
\hline Calcário calcítico & 0,456 & 0,304 & 0,098 & - \\
\hline Óleo de soja & 0,100 & 0,805 & 1,740 & 2,760 \\
\hline L - Lisina. HCl (78,4\%) & 0,208 & 0,212 & 0,217 & 0,222 \\
\hline DL - Metionina (99,0\%) & 0,020 & 0,033 & 0,049 & 0,066 \\
\hline L - Treonina (98,0\%) & 0,032 & 0,041 & 0,053 & 0,064 \\
\hline $\begin{array}{l}\text { L - Triptofano (99,0\%) } \\
\text { Suplementação mineral }\end{array}$ & $\begin{array}{c}- \\
0,050\end{array}$ & $\begin{array}{l}0,002 \\
0,050\end{array}$ & $\begin{array}{l}0,004 \\
0,050\end{array}$ & $\begin{array}{l}0,006 \\
0,050\end{array}$ \\
\hline Suplementação vitamínica ${ }^{(3)}$ & 0,400 & 0,400 & 0,400 & 0,400 \\
\hline Sal comum & 0,310 & 0,308 & 0,304 & 0,301 \\
\hline Inerte/Complexo enzimático ${ }^{(4)}$ & 1,285 & 0,040 & 0,012 & 0,005 \\
\hline BHT & 0,010 & 0,010 & 0,010 & 0,010 \\
\hline Total & 100 & 100 & 100 & 100 \\
\hline \multicolumn{5}{|l|}{ Composição calculada ${ }^{(5)}$} \\
\hline Energia metabolizável, kcal/kg & 3230 & 3230 & 3230 & 3230 \\
\hline Proteína bruta, \% & 15,53 & 15,53 & 15,53 & 15,53 \\
\hline Amido, \% & 50,57 & 47,77 & 44,05 & 40,17 \\
\hline FDN, \% & 11,80 & 12,35 & 12,73 & 13,09 \\
\hline FDA, \% & 4,24 & 5,07 & 5,86 & 6,63 \\
\hline Lisina dig., \% & 0,81 & 0,81 & 0,81 & 0,81 \\
\hline Metionina dig., \% & 0,27 & 0,27 & 0,28 & 0,29 \\
\hline Metionina + Cistina dig., \% & 0,50 & 0,50 & 0,50 & 0,50 \\
\hline Treonina dig., \% & 0,54 & 0,54 & 0,54 & 0,54 \\
\hline Triptofano dig., \% & 0,15 & 0,15 & 0,15 & 0,15 \\
\hline Cálcio, \% & 0,48 & 0,48 & 0,48 & 0,53 \\
\hline Fósforo disponível, \% & 0,25 & 0,25 & 0,25 & 0,25 \\
\hline Potássio, \% & 0,59 & 0,61 & 0,63 & 0,66 \\
\hline Sódio, \% & 0,16 & 0,16 & 0,16 & 0,16 \\
\hline
\end{tabular}

${ }^{1}$ Polpa cítrica, com ou sem complexo enzimático. ${ }^{2}$ Níveis de garantia por kg de ração: Cobre - 30mg, Zinco 160mg, Iodo - 1,900mg, Ferro - 100mg, Manganês $-70 \mathrm{mg}$, Selênio $-0,075 \mathrm{mg} .{ }^{3}$ Níveis de garantia por kg de ração: Vit. A - 10000 UI, Vit. D3 - 2500 UI, Vit. E - 18,12mg, Ácido fólico - 0,75mg, Pantotenato de cálcio 20mg, Biotina - 6mg, Niacina - 30mg, Piridoxina - 2,50mg, Riboflavina - 0,70mg, Tiamina - 2,50mg, Vit. B12 37,50mcg, Vit. K3 - 12,5mg, Colina - 783mg. ${ }^{4} 5 \mathrm{~g}$ de complexo enzimático por $100 \mathrm{~kg}$ de ração. ${ }^{5}$ Valores nutricionais dos ingredientes propostos por Rostagno et al. (2005), exceto polpa cítrica.

Os animais foram destinados ao abate quando atingiram o peso médio final de $98,81 \pm 10,64 \mathrm{~kg}$. Logo após o abate e a evisceração, a carcaça foi serrada longitudinalmente ao meio e pesada sem patas e cabeça, obtendo-se o peso da carcaça quente (PCQ). Em seguida, foi colocada por 24h em câmara fria $\left(-2^{\circ} \mathrm{C}\right)$, sendo, então, realizadas, na meia carcaça direita, as seguintes mensurações: espessura de toucinho (ET6) e profundidade de lombo (PL6), obtidas entre a última e a penúltima costelas, a $6 \mathrm{~cm}$ da linha dorsal média, com auxílio de um paquímetro, de modo a simular a leitura efetuada com a pistola de tipificação. Com os valores de PCQ, ET6 e 
PL6, foi calculada a porcentagem de carne magra (\%CM), conforme equação proposta por Guidoni (2000):

$$
\begin{gathered}
\% \mathrm{CM}=65,92-0,685 \times \mathrm{ET} 6+0,094 \times \text { PL6 - } \\
\text { 0,026 x PCQ. }
\end{gathered}
$$

Com os valores de \%CM e PCQ determinou-se o índice de bonificação (IB), sendo este um fator de correção do valor da carcaça, expresso em porcentagem, conforme a fórmula descrita por Fávero et al. (1997):

$$
\begin{gathered}
\mathrm{IB}=37,004721+0,094412 * \mathrm{PCQ}+1,144822 * \\
\% \mathrm{CM}-0,000053067 * \mathrm{PCQ} * \% \mathrm{CM}+ \\
0,000018336 * \mathrm{PCQ}^{2}+0,000409 * \% \mathrm{CM}^{2} .
\end{gathered}
$$

O valor final, em reais, recebido ( $\mathrm{R} \$$ suíno 98kg) foi determinado dentro do sistema de tipificação, com base no IB, PCQ e no preço do suíno vivo, conforme a fórmula descrita por Fávero et al. (1997):

R\$ suíno 98kg = (IB*[preço do quilograma do suíno vivo / 0,7145])*PCQ.

Pelo peso inicial (PI) médio de $25,71 \pm 7,51 \mathrm{~kg}$ e pelo preço da arroba do suíno vivo, determinouse o preço do suíno vivo inicial em junho de 2008, pela seguinte fórmula (Atzingen, 02/2009, Sossuino):

R\$ suíno 25kg = $($ Preço @ do suíno vivo *0,10) *PI.

Com os valores iniciais e finais obtidos com os animais e com o custo com alimentação, desconsiderando os custos operacionais e de depreciação das instalações, foram calculadas as receitas bruta e líquida parciais, referentes ao mês de agosto de 2008, em reais (R\$), conforme as seguintes fórmulas:

Receita bruta parcial $=\mathrm{R}$ \$ suíno $98 \mathrm{~kg}-\mathrm{R}$ \$ suíno

$$
25 \mathrm{~kg} \mathrm{e}
$$

Receita líquida parcial = Receita bruta parcial Custo com alimentação.

Ainda, foram realizadas simulações de receita líquida considerando-se os preços mensais do quilograma do suíno vivo, milho e farelo de soja, no período de janeiro a dezembro de 2008 (Tab. 4), de acordo com a ABCS (Bolsa..., 2009) e sendo fixados os preços dos demais ingredientes (Tab. 5), obtendo-se, assim, os valores das receitas líquidas parciais para cada mês, dentro do período citado.

Utilizou-se o delineamento em blocos ao acaso, em esquema fatorial $4 \times 2$, sendo quatro níveis de polpa cítrica, com ou sem adição do complexo enzimático, com nove repetições e um animal constituindo a parcela experimental. Os dados foram submetidos à análise de variância, utilizando-se o procedimento GLM do programa estatístico SAS (1998). As suposições para a normalidade dos resíduos foram verificadas pelo teste de Cramer-von Misses, de acordo com Everitt (1998). Para as diferenças significativas $(\mathrm{P}<0,05)$, os dados foram submetidos à análise de regressão polinomial, tendo como variável independente a porcentagem de PC adicionada às dietas.

Tabela 4. Preços (R\$/kg) do milho, farelo de soja e suínos vivos, no período de janeiro a dezembro de 2008

\begin{tabular}{lccc}
\hline Mês & Milho & Farelo de soja & Suíno vivo \\
\hline Janeiro & 0,49 & 0,77 & 2,86 \\
Fevereiro & 0,44 & 0,80 & 2,68 \\
Março & 0,43 & 0,76 & 2,87 \\
Abril & 0,42 & 0,74 & 2,70 \\
Maio & 0,44 & 0,75 & 2,96 \\
Junho & 0,44 & 0,83 & 3,25 \\
Julho & 0,46 & 0,84 & 3,52 \\
Agosto & 0,40 & 0,74 & 3,38 \\
Setembro & 0,38 & 0,77 & 3,44 \\
Outubro & 0,35 & 0,74 & 3,58 \\
Novembro & 0,32 & 0,75 & 2,88 \\
Dezembro & 0,34 & 0,74 & 2,86 \\
\hline
\end{tabular}


Avaliação econômica da utilização...

Tabela 5. Preços $(\mathrm{R} \$ / \mathrm{kg})$ dos demais ingredientes que compuseram as dietas experimentais

\begin{tabular}{cccccccc} 
& $\begin{array}{c}\text { Polpa } \\
\text { cítrica }\end{array}$ & $\begin{array}{c}\text { Calcário } \\
\text { calcítico }\end{array}$ & $\begin{array}{c}\text { Fosfato } \\
\text { bicálcico }\end{array}$ & $\begin{array}{c}\text { Sal } \\
\text { comum }\end{array}$ & $\begin{array}{c}\text { Óleo de } \\
\text { soja }\end{array}$ & $\begin{array}{c}\text { Suplemento } \\
\text { vitamínico }\end{array}$ & $\begin{array}{c}\text { Suplemento } \\
\text { mineral }\end{array}$ \\
\hline $\mathrm{R} \$ / \mathrm{kg}$ & 0,38 & 0,34 & 2,8 & 0,36 & 2,86 & 2,05 & 6,76 \\
\hline
\end{tabular}

\section{RESULTADOS E DISCUSSÃO}

Na Tab. 6 encontram-se os valores médios do peso final (PF), da espessura de toucinho (ET6), da profundidade de lombo (PL6), do peso da carcaça quente (PCQ), da porcentagem de carne magra (\%CM) e do índice de bonificação (IB), em função da porcentagem de inclusão da polpa cítrica, com ou sem adição do complexo enzimático.

Tabela 6. Valores médios e coeficientes de variação (CV) para peso final (PF), da espessura de toucinho (ET6), da profundidade de lombo (PL6), do peso da carcaça quente (PCQ), da porcentagem de carne magra (\%CM) e do índice de bonificação (IB), segundo a porcentagem de inclusão de polpa cítrica, com $(+)$ ou sem (-) adição do complexo enzimático

\begin{tabular}{lcccccccccc}
\multirow{2}{*}{ Variável } & \multicolumn{2}{c}{$0 \%$} & \multicolumn{2}{c}{$5 \%$} & \multicolumn{2}{c}{$10 \%$} & \multicolumn{2}{c}{$15 \%$} & \multicolumn{1}{c}{ CV, } \\
\cline { 2 - 10 } & - & + & - & + & - & + & - & + & $\%$ \\
\hline PF, kg & 99,33 & 95,91 & 99,56 & 99,24 & 99,25 & 94,08 & 91,23 & 98,14 & 9,58 \\
ET6, mm & 10,93 & 12,81 & 12,58 & 12,91 & 13,77 & 9,62 & 11,32 & 10,91 & 26,56 \\
PL6, mm & 57,03 & 55,92 & 55,80 & 57,70 & 57,37 & 57,90 & 53,63 & 56,66 & 8,34 \\
PCQ, kg & 71,41 & 68,90 & 71,48 & 71,85 & 70,56 & 66,91 & 63,27 & 68,90 & 9,58 \\
CM, \% & 61,94 & 60,61 & 60,69 & 60,63 & 60,04 & 63,03 & 61,53 & 61,98 & 3,51 \\
IB, \% & 116,08 & 113,54 & 114,61 & 114,57 & 113,84 & 116,97 & 115,45 & 115,99 & 3,52 \\
\hline
\end{tabular}

A porcentagem da inclusão de polpa cítrica nas dietas, com ou sem adição do complexo enzimático, não influenciou $(\mathrm{P}>0,05)$ as características de carcaça. Estes resultados foram semelhantes aos observados por Vieira et al. (2003), que também não notaram efeito de diferentes porcentagens de fibra sobre estas variáveis, para suínos em terminação.

Na Tab. 7 encontram-se os dados referentes aos custos do $\mathrm{kg}$ da dieta e aos custos com alimentação, às receitas bruta e líquida parciais, em função da porcentagem de inclusão da polpa cítrica, com ou sem adição do complexo enzimático, correspondentes ao mês de agosto de 2008.
A inclusão de PC nas dietas influenciou $(\mathrm{P}<0,05)$ as variáveis avaliadas, e não houve efeito $(\mathrm{P}>0,05)$ da presença ou não do complexo enzimático. Também não se observou efeito da interação de PC versus complexo enzimático.

Para os custos com alimentação (Fig. 1), observou-se aumento linear $(\mathrm{P}=0,0190)$, enquanto para as receitas bruta e líquida (Fig. 1) parciais, foram encontradas reduções lineares ( $\mathrm{P}=0,0328$ e 0,0013 , respectivamente), à medida que aumentaram as porcentagens de PC nas dietas.

Tabela 7. Valores médios dos custos do kg da dieta (CR) e dos custos com alimentação (CCA) e das receitas bruta (RBP) e líquida (RLP) parciais, observadas para os suínos segundo a porcentagem de inclusão de polpa cítrica, com (+) ou sem (-) adição do complexo enzimático

\begin{tabular}{lccccccccc} 
Valor, & \multicolumn{2}{c}{$0 \%$} & \multicolumn{3}{c}{$5 \%$} & \multicolumn{3}{c}{$10 \%$} & \multicolumn{3}{c}{$15 \%$} & \multirow{2}{*}{ CV, \% } \\
\cline { 2 - 10 } \multicolumn{1}{c}{ R } & - & + & - & + & - & + & - & + & \\
\hline CR & 0,54 & 0,54 & 0,59 & 0,59 & 0,62 & 0,62 & 0,65 & 0,65 & - \\
CCA $^{\text {a }}$ & 106,97 & 100,30 & 116,66 & 112,35 & 121,06 & 108,73 & 111,25 & 120,71 & 15,30 \\
RBP $^{\text {a }}$ & 285,25 & 265,81 & 280,01 & 279,74 & 270,98 & 259,24 & 235,88 & 267,18 & 14,02 \\
RLP $^{\text {a }}$ & 178,29 & 165,51 & 163,35 & 167,40 & 149,92 & 150,51 & 124,63 & 146,47 & 22,44 \\
\hline
\end{tabular}

${ }^{\mathrm{a}}$ Efeito linear da porcentagem de inclusão de polpa cítrica, sem complexo enzimático. 

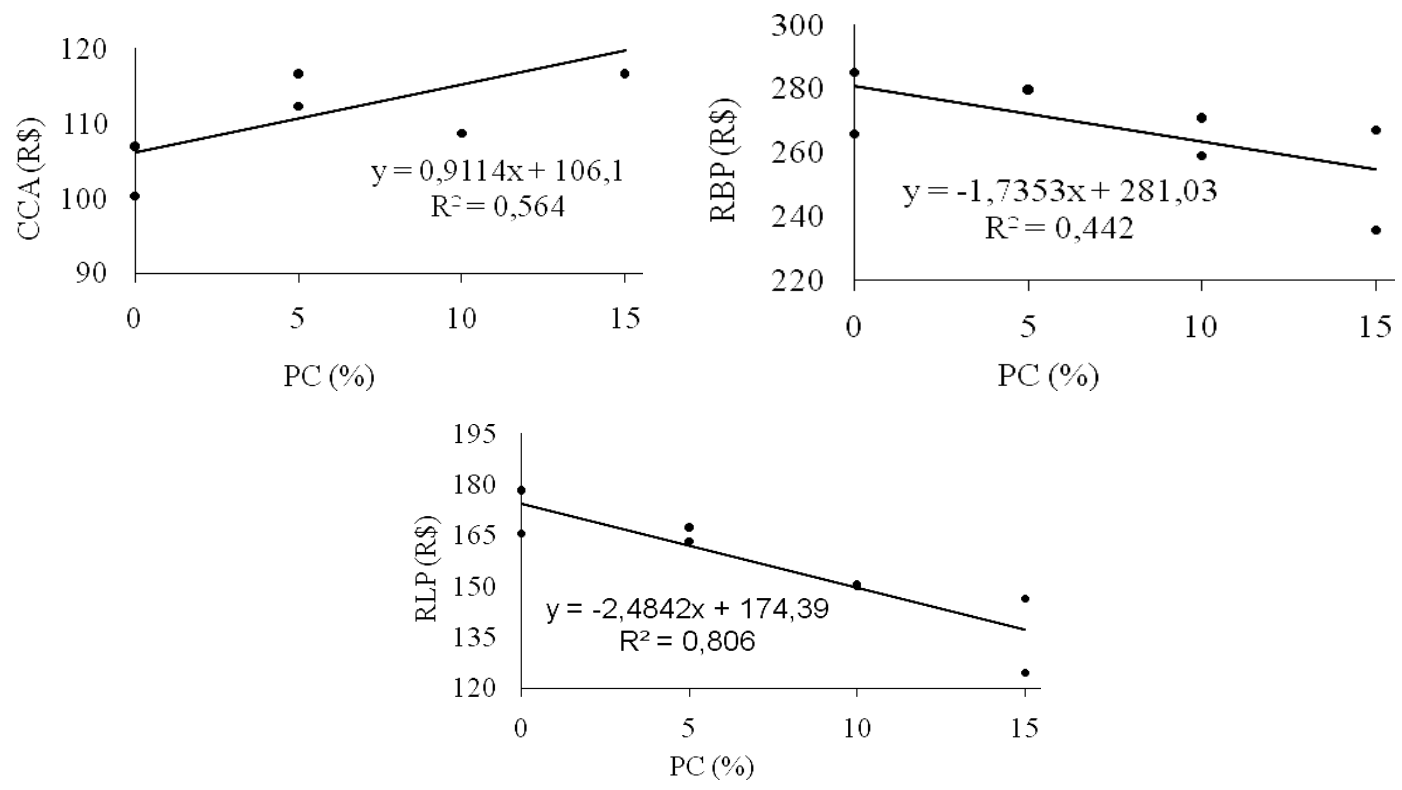

Figura 1. Custo com alimentação (CCA) e receitas bruta (RBP) e líquida (RLP) parciais, referentes ao mês de agosto de 2008, em função da porcentagem de adição de polpa cítrica (PC), com ou sem adição do complexo enzimático, às dietas de suínos.

Embora não tenha havido diferenças entre tratamentos $(\mathrm{P}>0,05)$ quanto às ET6, PL6, PCQ, $\% \mathrm{CM}$ e IB, notou-se que os custos com alimentação elevaram-se linearmente conforme aumentaram as porcentagens de polpa cítrica nas dietas (Fig. 1). Deve-se considerar, no entanto, que, para manter as dietas isonutritivas, com o aumento nas porcentagens de polpa cítrica, houve necessidade de aumentar a quantidade de óleo de soja e de aminoácidos sintéticos nas rações, o que elevou seus custos e reduziu as receitas bruta e líquida parciais.

Dados semelhantes foram observados por Quadros et al. (2008), que, ao utilizarem um ingrediente fibroso nas dietas, também adicionaram óleo para equilibrar a energia delas, o que acarretou diminuição na receita líquida. Segundo Watanabe et al. (2009), em função do preço da polpa cítrica e do aumento da porcentagem desse ingrediente na dieta, não se justifica sua utilização.

Na Tab. 8 encontram-se os dados referentes à receita líquida parcial em função da porcentagem de inclusão de polpa cítrica, com ou sem adição do complexo enzimático, ao longo do ano de 2008. Observou-se redução linear $(\mathrm{P}<0,05)$ conforme aumentou a porcentagem de inclusão do subproduto.

A viabilidade econômica do uso da polpa cítrica na dieta de suínos está vinculada, principalmente, ao preço do óleo, o qual supre a energia da dieta à medida que aumenta a porcentagem desse ingrediente. Assim, como no período estudado seu preço estava relativamente alto, a receita líquida apresentou redução linear com o aumento de inclusão de PC, para todos os meses de 2008. Outra razão para justificar os resultados observados pode ser a necessidade de elevar a inclusão de aminoácidos sintéticos à medida que aumentava a porcentagem de polpa cítrica.

Fraga et al. (2008) observaram que somente quando as diferenças de preços entre o ingrediente energético das dietas, normalmente o milho, e o diluente energético, um ingrediente rico em fibra, fossem superiores a quatro vezes, é que esta substituição podia ser economicamente viável. Watanabe et al. (2009) concluíram que a polpa cítrica podia melhorar o índice de bonificação quando utilizada em programa de restrição alimentar qualitativa para suínos pesados, porém ressaltaram que o preço do ingrediente tem que ser bem atrativo. 
Tabela 8. Receita líquida parcial, sob diferentes cenários de preços do milho, farelo de soja e suíno vivo, durante o ano de 2008, segundo a porcentagem de inclusão de polpa cítrica, com (+) ou sem (-) a adição do complexo enzimático nas rações de suínos

\begin{tabular}{|c|c|c|c|c|c|c|c|c|c|c|}
\hline \multirow{2}{*}{ Mês } & \multicolumn{2}{|c|}{$0 \%$} & \multicolumn{2}{|c|}{$5 \%$} & \multicolumn{2}{|c|}{$10 \%$} & \multicolumn{2}{|c|}{$15 \%$} & \multirow{2}{*}{$\mathrm{CV}, \%$} & \multirow{2}{*}{$\begin{array}{l}\text { Valor de } \\
\text { P: efeito } \\
\text { linear }\end{array}$} \\
\hline & - & + & - & + & - & + & - & + & & \\
\hline Janeiro & 112,78 & 104,12 & 97,42 & 101,59 & 85,82 & 95,83 & 68,32 & 83,38 & 29,01 & 0,0005 \\
\hline Fevereiro & 103,64 & 95,65 & 88,46 & 92,50 & 76,97 & 86,79 & 60,40 & 74,22 & 30,31 & 0,0003 \\
\hline Março & 127,22 & 117,77 & 112,00 & 116,04 & 99,88 & 109,38 & 81,00 & 96,86 & 25,86 & 0,0004 \\
\hline Abril & 166,36 & 155,23 & 150,34 & 154,75 & 137,53 & 147,08 & 115,14 & 134,57 & 20,86 & 0,0005 \\
\hline Maio & 153,42 & 142,55 & 136,80 & 141,12 & 124,10 & 136,57 & 102,51 & 121,28 & 22,85 & 0,0006 \\
\hline Junho & 159,47 & 147,84 & 142,49 & 146,62 & 129,29 & 138,68 & 106,25 & 125,99 & 22,92 & 0,0005 \\
\hline Julho & 159,34 & 147,26 & 142,47 & 146,30 & 128,87 & 137,77 & 104,85 & 125,00 & 23,37 & 0,0004 \\
\hline Agosto & 178,29 & 165,51 & 163,35 & 167,40 & 149,92 & 158,76 & 124,63 & 146,48 & 21,10 & 0,0012 \\
\hline Setembro & 106,67 & 97,17 & 90,48 & 93,65 & 77,50 & 85,88 & 62,53 & 72,78 & 30,53 & 0,0001 \\
\hline Outubro & 101,40 & 91,91 & 85,21 & 88,16 & 72,06 & 80,16 & 56,96 & 66,96 & 32,38 & 0,0001 \\
\hline Novembro & 118,92 & 109,70 & 102,55 & 106,12 & 89,77 & 98,52 & 75,01 & 85,43 & 25,99 & 0,0001 \\
\hline Dezembro & 116,87 & 107,80 & 100,44 & 104,12 & 87,86 & 96,86 & 73,55 & 83,85 & 26,55 & 0,0001 \\
\hline
\end{tabular}

\section{CONCLUSÕES}

A utilização de polpa cítrica, com ou sem adição do complexo enzimático, não consegue reduzir os custos com alimentação, não sendo economicamente viável sua inclusão nas dietas de suínos nas fases de crescimento e terminação.

\section{AGRADECIMENTOS}

Ao CNPq, pelo financiamento do projeto.

\section{REFERÊNCIAS BIBLIOGRÁFICAS}

BELLAVER, C.; LUDKE, J. Considerações sobre os alimentos alternativos para dietas de suínos. In: ENCONTRO INTERNACIONAL DOS NEGÓCIOS DA PECUÁRIA, 1., 2004, Cuiabá. Palestras..., 2004. CDROM.

BHAT, M.K. Cellulases and related enzymes in biotechnology. Biotechnol. Adv., v.18, p.355383, 2000.

BOLSA de suínos. ABCS, 2009. Disponível em: $<$ http://www.suinopaulista.com.br $>$. Acessado em: 20 jan. 2009.

EVERITT, B.S. The Cambridge dictionary of statistics in the medical sciences, 2. ed. Cambridge: Cambridge University, 1998, 360p.

FÁVERO, J.A.; GUIDONI, A.L.; BELLAVER, C. Predição do índice de valorização de carcaça suína em função do peso e do percentual de carne. In: CONGRESSO DA ASSOCIAÇÃO BRASILEIRA DE VETERINÁRIOS ESPECIALISTAS EM SUÍNOS, 8., 1997, Concórdia. Anais...Concórdia: EMBRAPACNPSA, 1997. p.405-406. (Resumo).
FRAGA, A.L.; THOMAZ, M.C.; MARTINS, M.I.E.G. et al. Avaliação econômica do uso da restrição alimentar qualitativa para suínos com elevado peso de abate. Rev. Bras. Zootec., v.37, p.1050-1054, 2008.

GUIDONI, A.L. Melhoria dos processos para tipificação de carcaça suína no Brasil. In: CONFERÊNCIA INTERNACIONAL VIRTUAL SOBRE QUALIDADE DE CARNE SUÍNA, 1., 2000, Concórdia. Anais eletrônicos... Disponível em: <http://www.cnpsa.embrapa.br/pork>. Acessado em: 22 jun. 2007.

HISTÓRIA da laranja e farelo de polpa cítrica ("Pellets"). ABECITRUS, 2009. Disponível em: <www.abecitrus.com.br>. Acessado em: 27 jan. 2009.

QUADROS, A.R.B.; MOREIRA, I.; FURLAN, A.C. et al. Inclusão de diferentes níveis de casca de soja moída em dietas isoenergéticas para suínos em crescimento e terminação. Cienc. Rural, v.38, p.463-469, 2008.

ROSTAGNO, H.S.; ALBINO, L.F.T.; DONZELE, J.L. et al. Tabelas brasileiras para aves e suínos: composição de alimentos e exigências nutricionais. Viçosa: UFV, 2005. $186 \mathrm{p}$.

SARAIVA, E.P.; BARROS, L.S.; SOARES, C.A. et al. Utilização de cana-de-açúcar em dietas de suínos dos 30 aos 60kg. In: REUNIÃO ANUAL DA SOCIEDADE BRASILEIRA DE ZOOTECNIA, 43., 2006, João Pessoa. Anais... João Pessoa: SBZ, 2006. CDROM. (Resumo).

SAS user's guide: statistic. Cary: SAS Institute, 1998. 
VIEIRA, A.S.; BARBOSA, H.C.A.; ALMEIDA, F.Q. et al. Qualidade de carcaça de suínos em terminação submetidos a diferentes níveis de restrição alimentar. In: CONGRESSO DE PESQUISA CIENTÍFICA DA UFRRJ, 1., 2003, Rio de Janeiro. Anais... Rio de Janeiro, 2003. p.1-5. (Resumo).
WATANABE, P.H.; THOMAZ, M.C.; MARTINS, M.I.E.G. et al. Receita bruta e líquida parcial e custo de dietas contendo polpa cítrica para suínos abatidos com $130 \mathrm{~kg}$ de peso. Arq. Bras. Med. Vet. Zootec., v.61, p.203-210, 2009. 